\title{
SHIP AS A SOURCE OF THE SEA POLLUTION WITH OIL
}

\author{
Adam Stelmaszewski, Zbigniew Otremba \\ Gdynia Maritime University, Department of Physics \\ Morska Street 83-87, 81-225 Gdynia, Poland \\ tel.: +4858 6901284, +48586901385, fax: +48586206701 \\ e-mail:stel@am.gdynia.pl,zotremba@am.gdynia.pl
}

\begin{abstract}
The subject of marine vessel as a source of the sea pollution was taken because of very adverse impact of petroleum pollutants on the natural environment. Oil pollutions concern especially marine environment. However, petroleum inflows to the sea from many different sources, exploitation of the fleet are one of the significant causes of oil presence in the marine environment. MARPOL Convention requires the states parties thereto to monitor the state of contamination [3] and this is a second reason of taking this subject.

During the past years, several tests of petroleum content in the Gulf of Gdansk were made by the Physics Department of Gdynia Maritime University. In total 115 samples of water were collected and analyzed during the period from 2004 to 2009 year in the Gulf of Gdansk, which is an area of intense ships traffic because of two great complexes of harbours located in Gdansk and in Gdynia. These tests were carried out with the help of Institute of Oceanology Polish Academy of Sciences during cruises of the r.v. "Oceania". Petroleum concentration in seawater was determined by means of improved fluorescence method. Oil in water concentration ranged from value below of the detection limit, that is $10^{-9}(<1 \mathrm{ppb})$, up to $3.5 \cdot 10^{-7}$ (350 ppb). Average concentration of oil was $4.3 \cdot 10^{-8}(43 \mathrm{ppb})$. Obtained results confirmed that Vistula River could be a source of petroleum pollution of the Gulf of Gdansk. Apart from this, vessels are the significant sources of oil in the seawater too. The most polluted places were founded in the area where ships crossed the Gulf of Gdansk.
\end{abstract}

Keywords: maritime transport, seawater, petroleum, environmental protection, Gulf of Gdansk

\section{Introduction}

Oils have an adverse impact on the natural environment. This has been reported in many papers. A number of monographs $[2,3,5]$ present comprehensive lists of the relevant papers. Petroleum was acknowledged to be marine pollutant already in 1954 [4] (IMO 2006), long before any other substances and before the mentioned reports too. In 1973, IMO adopted the International Convention for the Prevention of Pollution from Ships, now known universally as MARPOL, which has been amended by Protocols adopted in 1978 and 1997 and kept updated through other relevant amendments [5]. According to the Convention, the term "oil" denotes any kind of crude oil and any petrochemical product, like fuel or grease oil, as well as a product of petroleum transformation in the marine environment. The Convention regulates any question, which refers to pollution of the sea and has greatly contributed to a significant decrease in pollution from international shipping. MARPOL requires the states parties thereto to protect against pollution of water bodies belonging to them and to monitor the state of contamination. The significant reductions of pollution generated by ships have been achieved by addressing technical and operational element issues.

In spite of such progress, oils enter the marine environment from numerous sources. Chronic release from natural seeps and runoff from land sources are responsible for the majority of petroleum hydrocarbon input to the world's oceans. The last assessment places the current global rate of natural seepage of petroleum at 600,000 tones per year, with a range of 200,000 to 2,000,000 tones per year [5]. The estimate of annual runoff from land-based sources is 140,000 tones with even wider limits: the minimum estimate is 6,800 tones and the maximum estimate is 5,000,000 tones (ibidem). The best estimate of the worldwide annual spillage from tankers is about 100,000 tones. 
The Baltic Sea is a marine are where the vessel traffic is very intense. The Pomeranian Bay and the Gulf of Gdansk are two basins in Polish zone where the shipping is most intense. For two last decades, aerial surveillance evidence that the Baltic Sea is still exposed to oil pollution but the level of risk fortunately decreases. This trend also applies to Polish marine areas - the absolute number of detections decreases as well as the rate relative to the time duration of flight inspection (Fig. 1). Each year the oil spots are detected in areas of approach to ports. Fig. 2 presents exemplary results of aerial inspection at the Southern Baltic. One can notice increased density of oil-contaminated areas in the Gulf of Gdansk.

Moreover, two main Polish rivers inflow to the Southern Baltic sea. Therefore, determination of pollutants in these basins is necessary. The paper presents concentration of petroleum pollutants in seawater in the Gulf of Gdansk determined during several research cruises of the r.v. Oceania in years from 2004 to 2009 .

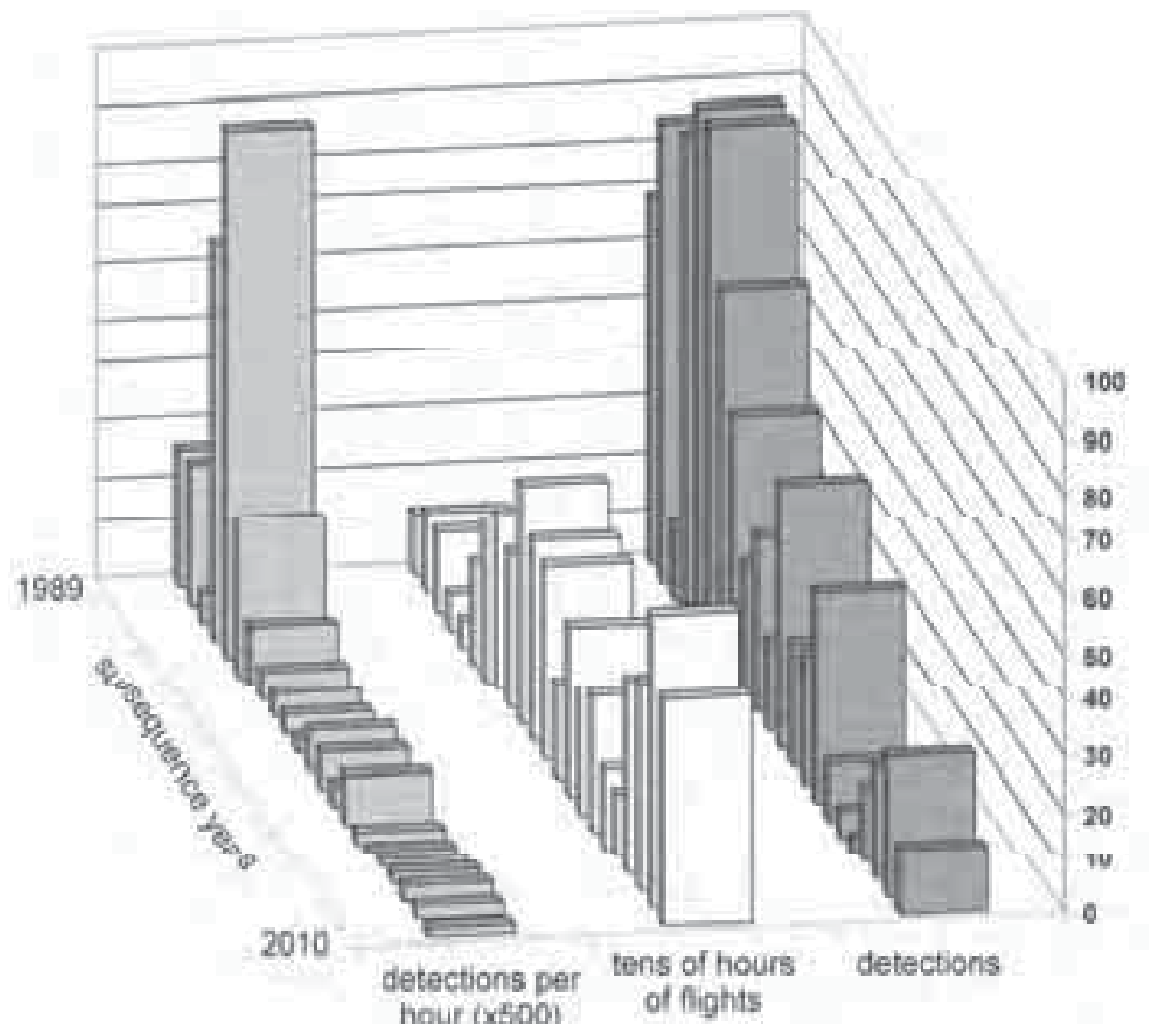

Fig. 1. Aerial detections of oil in Polish marine areas during 1998-2010. Developed after data from HELCOM portal (www.helcom.fi)

\section{Methods and materials}

Seawater was sampled from the board of r.v. Oceania. A $1.5 \mathrm{dm}^{3}$ bottle was filled with water sampled at a depth of $1 \mathrm{~m}$. A fixed amount of water $\left(1.2 \mathrm{dm}^{3}\right)$ was extracted with hexane. Throughout this process, the extracts were stored in darkness at a temperature below $5^{\circ} \mathrm{C}$. Both the water and the hexane were weighed. The oil concentration was determined by the improved fluorescence method [8]. In this method, the intensity of light emitted by the extract is measured. The wavelength of the exciting radiation is $210 \mathrm{~nm}$ and that of the fluorescence is $295 \mathrm{~nm}$. Result of this measurement $\mathrm{w}$ is compared with the intensity of luminescence of a standard - a solution of artificially aged crude North Sea oil. This determination is based on the linear relation between the oil concentration and the intensity of fluorescence $w$. The concentration $C$ of petroleum in the water is calculated from the following expression: 


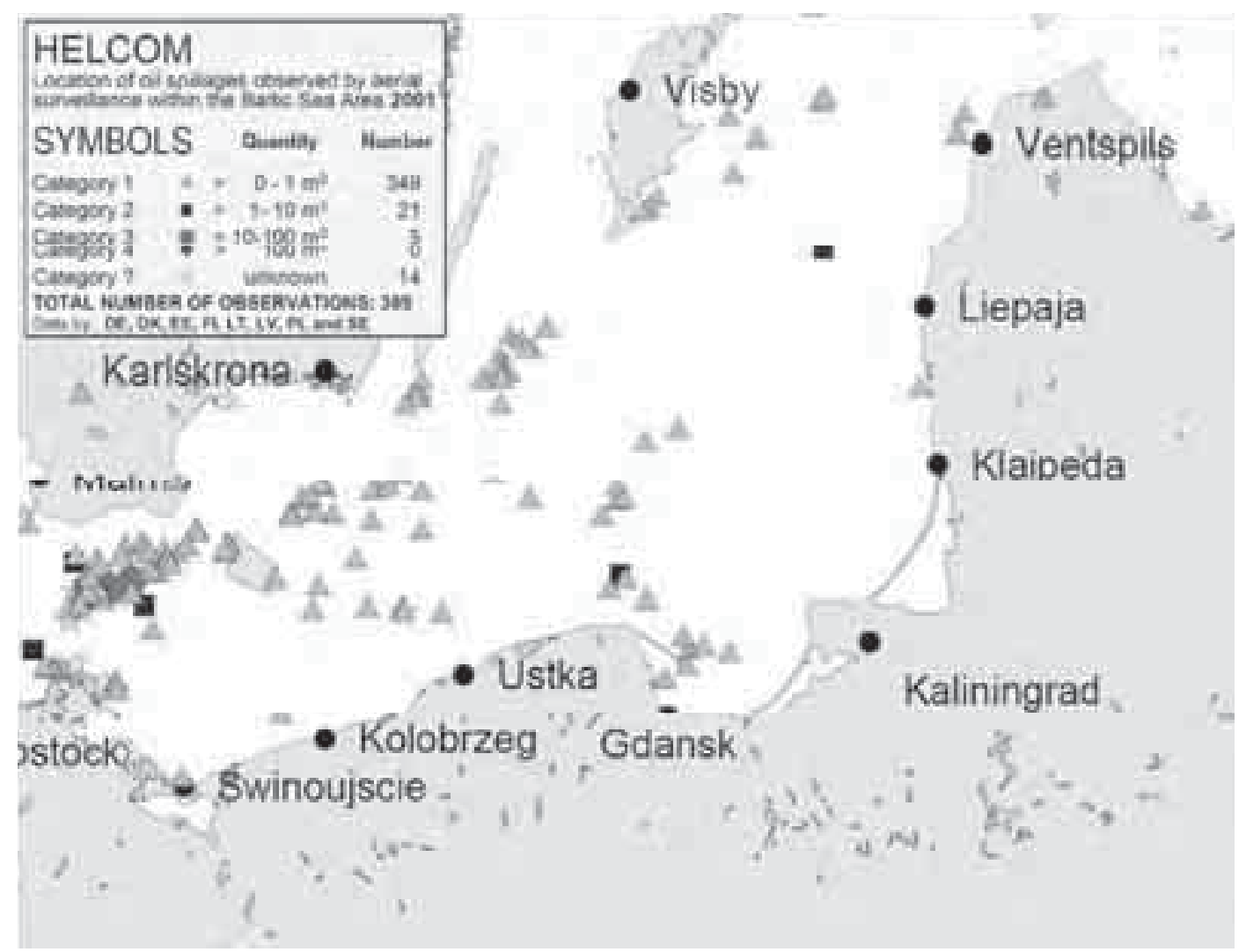

Fig. 2. Aerial detections of oil during air surveillance in one year in the Southern Baltic-example. Processed after HELCOM portal (www.helcom.fi)

$$
C=\frac{w}{w_{r}} \frac{m}{M} C_{r}
$$

where:

$C-$ oil concentration in water,

$w$ - fluorescence intensity of extract,

$w_{r}$ - fluorescence intensity of standard,

$m$ - mass of extract,

$M-$ mass of sample of tested water,

$C_{r}-$ standard concentration.

\section{Results}

Investigated area covers the polish zone of the Gulf of Gdansk bounded on the north by the Hel Peninsula and the parallel $54^{\circ} 40^{\prime}$ N. 115 samples of seawater were tested. The concentration of petroleum pollutants in the water ranges from below $1 \mu \mathrm{g} / \mathrm{kg}$ (limit of detection) to $356 \mu \mathrm{g} / \mathrm{kg}$. Average concentration is $43 \mu \mathrm{g} / \mathrm{kg}$ and standard deviation of these results is $63 \mu \mathrm{g} / \mathrm{kg}$. Most of the results (over $75 \%$ ) do not exceed the average concentration.

Fourteen most polluted points were selected for the further discussion. Tab. 1 presents coordinates of the points, where concentration of oil exceeds $100 \mu \mathrm{g} / \mathrm{kg}$. Fig. 3 indicates these places. Position of some of these points suggest Vistula river as a possible source of contamination. Great inflow of water - mean daily discharge over 93 millions $\mathrm{m}^{3}$ - deliver various dangerous substances to the sea [7]. Impact of the Vistula on the Gulf of Gdansk is detected to the north and to the east from the rivers mouth. The river water mixes with the seawater and pollutants migrate towards northeast direction $[6,9]$. 
Tab. 1. Petroleum concentration $C$ in seawater in most polluted points of the Gulf of Gdansk with coordinates of the points and date of sampling. Numbers of measurements are harmonized with numbers of sampling points in Fig. 1

\begin{tabular}{|c|c|c|c|}
\hline No. & $C[\mu \mathrm{g} / \mathrm{kg}]$ & coordinates & date of sampling \\
\hline 1. & 356 & $54^{\circ} 27^{\prime} \mathrm{N} 18^{\circ} 40^{\prime} \mathrm{E}$ & $2005-11-21$ \\
\hline 2. & 269 & $54^{\circ} 30^{\prime} \mathrm{N} 18^{\circ} 45^{\prime} \mathrm{E}$ & $2005-11-21$ \\
\hline 3. & 246 & $54^{\circ} 23^{\prime} \mathrm{N} 18^{\circ} 58^{\prime} \mathrm{E}$ & $2008-03-26$ \\
\hline 4. & 235 & $54^{\circ} 30^{\prime} \mathrm{N} 19^{\circ} 07^{\prime} \mathrm{E}$ & $2008-03-26$ \\
\hline 5. & 211 & $54^{\circ} 30^{\prime} \mathrm{N} 19^{\circ} 07^{\prime} \mathrm{E}$ & $2008-03-26$ \\
\hline 6. & 202 & $54^{\circ} 30^{\prime} \mathrm{N} 18^{\circ} 57^{\prime} \mathrm{E}$ & $2008-03-26$ \\
\hline 7. & 192 & $54^{\circ} 24^{\prime} \mathrm{N} 19^{\circ} 00^{\prime} \mathrm{E}$ & $2008-03-26$ \\
\hline 8. & 184 & $54^{\circ} 26^{\prime} \mathrm{N} 18^{\circ} 45^{\prime} \mathrm{E}$ & $2008-03-26$ \\
\hline 9. & 181 & $54^{\circ} 30^{\prime} \mathrm{N} 18^{\circ} 57^{\prime} \mathrm{E}$ & $2005-11-21$ \\
\hline 10. & 178 & $54^{\circ} 25^{\prime} \mathrm{N} 18^{\circ} 53^{\prime} \mathrm{E}$ & $2005-11-21$ \\
\hline 11. & 113 & $54^{\circ} 37^{\prime} \mathrm{N} 18^{\circ} 53^{\prime} \mathrm{E}$ & $2008-03-26$ \\
\hline 12. & 113 & $54^{\circ} 23^{\prime} \mathrm{N} 18^{\circ} 52^{\prime} \mathrm{E}$ & $2005-11-21$ \\
\hline 13. & 105 & $54^{\circ} 34^{\prime} \mathrm{N} 18^{\circ} 50^{\prime} \mathrm{E}$ & $2006-05-20$ \\
\hline 14. & 104 & $54^{\circ} 23^{\prime} \mathrm{N} 19^{\circ} 15 \mathrm{E}$ & \\
\hline
\end{tabular}

Entire tested basin could be divided for two parts: the area, where the Vistula impact occurs, that is east of the river mouth, and the area west of the mouth, where does not direct impact of the river. It was assumed that contamination might have flow down the Vistula River if a point is to the east of the meridian of $18^{\circ} 55^{\prime}$ ' (dotted white line in Fig. 3). Average concentration of oil in the water is estimated as $5.0 \cdot 10^{-8}$ in the east-area and that is more than in the west-area, where the mean concentration is $3.8 \cdot 10^{-8}$. This fact confirms petroleum runoff the land based sources with the river water. It is important here that eight of the fourteen highest concentrations refer to the places west of the boundary meridian.

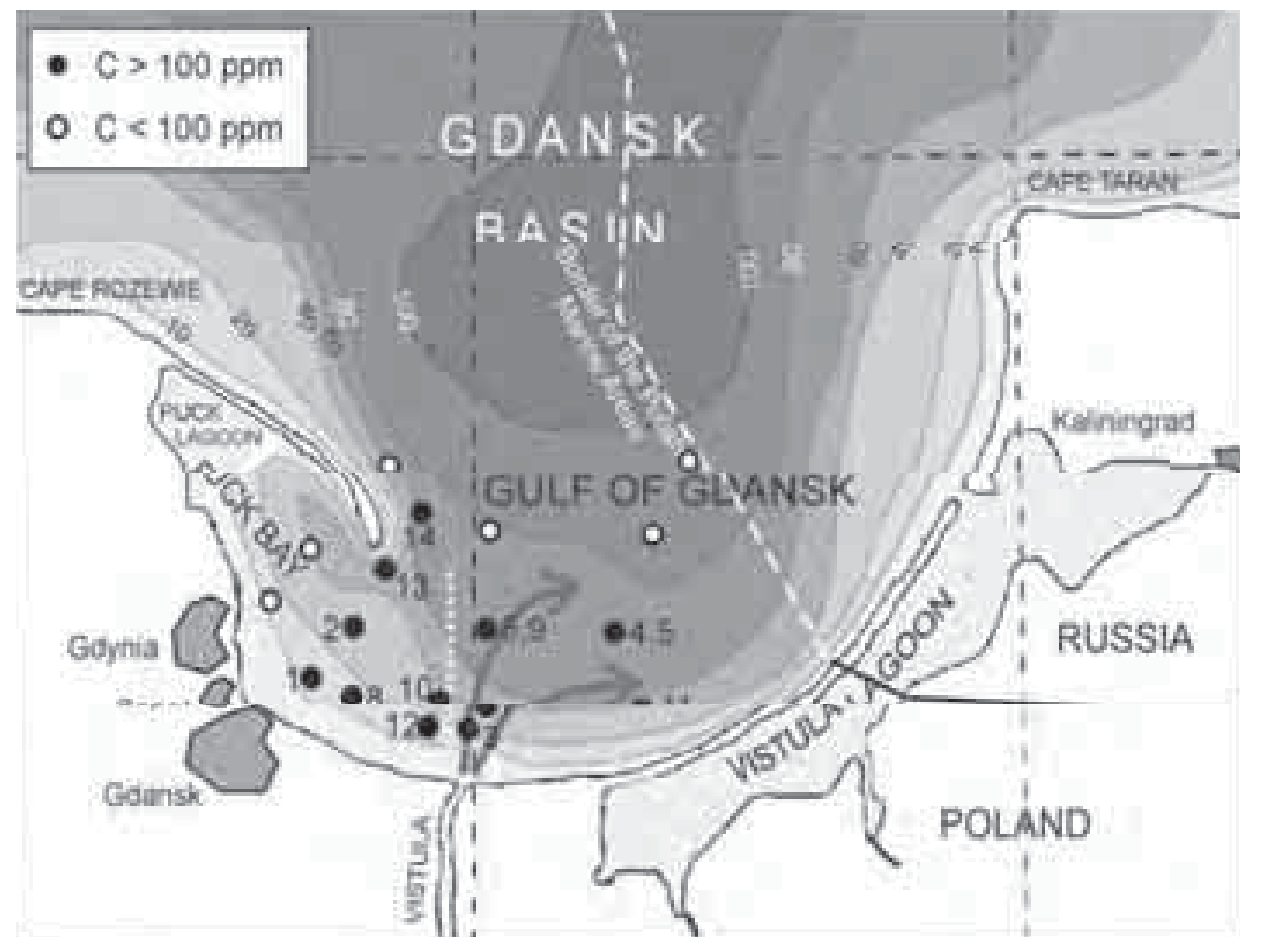

Fig. 3. Map of investigated area in the Gulf of Gdansk with points of water sampling. Dotted white line indicates offset yield of Vistula River disturbance area, narrows - the most probable direction of spread of the Vistula waters 
One should be paid to two issues in the analysis of these results. A large area polluted with oil has not been found in the Gulf of Gdansk. There were no reports that at the same time a high level of contamination was in the adjacent points. Any of the most polluted places was a separate point in relative clean area. These contaminations may have been the effects of incidental oil spills. Moreover, intense ship traffic characterizes entire Gulf of Gdansk. Not only merchant ships, but also numerous fishing vessels of different sizes are still present in the both parts of investigated area. Regardless of possible runoff of petroleum with river water, fleet exploitation is the only explanation for the incidental oil spills, because there is not other possible source of petroleum in the Gulf of Gdansk like oil/gas extracting platform or pipeline.

\section{Summary}

Obtained results confirmed that Vistula River is possible source of petroleum in the Gulf of Gdansk. Regardless of runoff with the river water, oil spills occurs in the Gulf of Gdansk despite that is a protected area. Marine vessel is only source of incidental oil spill. The studies allow conclude that operation of the fleet is significant source of the sea pollution with petroleum.

It worth to be added that the present results are somewhat accidental, since the measurements are rare, and spotlights. So there are still searching ways to more easily obtain information about the content and origin of residual oil in marine areas [1].

\section{References}

[1] Baszanowska, E., Otremba, Z., Rohde, P., Zieliński, O., Adoption of the time resolved fluorescence to oil type identification, Journal of KONES Powertrain and Transport, Vol. 18, No. 2, pp. 25-29, 2011.

[2] GESAMP (Joint Group of Experts on the Scientific Aspects of Marine Environmental Protection), Impact of oil and related chemicals and wastes on the marine environment, Rep. Stud. No. 50, 180 pp., 1993.

[3] GESAMP, Estimates of oil entering the marine environment from sea-based activities, Rep. Stud. No. 75, 96 pp., 2007.

[4] IMO (International Maritime Organization), International Convention for the Prevention of Pollution from Ships MARPOL73/78, Consolidated Edition 2006, London, 487 pp., 2006.

[5] NRC (Committee on Oil in the Sea, National Research Council), Oil in the Sea III: Inputs, Fates, and Effects, The National Academies Press, Washington, 280 pp., 2003.

[6] Pastuszak, M., The hydrochemical and biological impact of the River Vistula on the pelagic system of the Gulf of Gdansk in 1994. Part 1. Variability in nutrient concentration, Oceanologia, 37 (2), pp. 181-205, 1995.

[7] Pempkowiak, J., Kupryszewski, G., The input of organic matter to the Baltic Sea from the River Vistula, Oceanologia, 12, pp. 79-98, 1980.

[8] Stelmaszewski, A., Determination of petroleum pollutants in coastal waters of the Gulf of Gdansk, Oceanologia, 51(1), pp. 85-92, 2009.

[9] Zajączkowski, M., Darecki, M., Szczuciński, W., Report on the development of the Vistula river plume in the coastal waters of the Gulf of Gdansk during the May 2010 flood, Oceanologia, 52(2), pp. 311-317, 2010. 